1. MBBS, FCPS (Obs and Gynae) Senior Medical Officer

Quaid E Azam Medical College, Bahawal Victoria Hospital Bahawalpur.

2. MBBS, FCPS (Obs and Gynae) Senior Registrar

Bahawal Victoria Hospital Bahawa Pur.

3. MBBS, FCPS (Obs \& Gynae)

Medical Officer

Shahbaz Sharif Hospital, Multan

4. MBBS

House Officer

Nishtar Medical College, Multan.

Correspondence Address:

Dr. Aisha Javed

Department of Obs and Gyne

Bahawal Victoria Hospital Bahawal

Pur.

draishafcps@yahoo.com

Article received on:

28/04/2020

Accepted for publication:

30/03/2021

\section{Comparison of efficacy of intramyometrial versus intramuscular prostaglandin F2 $\alpha$ (PGF2 $\alpha)$ in the management of primary postpartum hemorrhage due to uterine atony.}

\begin{abstract}
Saira Kanwal ${ }^{1}$, Aisha Javed ${ }^{2}$, Sidra Saba ${ }^{3}$, Afifa Batool Gillani ${ }^{4}$
ABSTRACT... Objective: To determine the better route of prostaglandin F2a either intramyometrial or intramuscular for the management of uterine atony and to prevent surgical intervention. Study Design: Randomized Controlled Trial. Settings: Bahawal Victoria Hospital. Period: Feb 2018 to July 2018. Material \& Method: A total of 266 patients with primary PPH due to uterine atony of 20 to 39 years of age were enrolled in the study. Patients of primary $\mathrm{PPH}$ due to bleeding disorders, ruptured uterus, on anticoagulant therapy and hypersensitivity to prostaglandin were excluded. Patients were divided randomly into two groups i.e. Group A (for intramyometrial injection) \& Group B (for intramuscular injection). Outcome variables like arrest of bleeding within 30 minutes after start of treatment (efficacy) were noted for successful or unsuccessful outcome. Results: The mean age of women in group A was $26.94 \pm 4.43$ and in group $B$ was $26.21 \pm 4.09$ years $(p=0.005)$. The mean parity in group $A$ was $2.92 \pm 0.87$ and in group $B$ was $2.93 \pm 0.98(p=0.8579)$. Efficacy was $82.71 \%$ in group A (Intramyometrial group) and $91.73 \%$ in group B (Intramuscular group) with p-value of 0.0276 . Conclusion: This study concluded that intramuscular prostaglandin F2a has better efficacy i.e. $91.73 \%$ in a patient of uterine atony for management of primary PPH as compared to intramyometrial rout of administration for prostaglandin F2a.
\end{abstract}

Key words: $\quad$ 2nd Line Agents, Arrest of Bleeding, Oxytocin, Postpartm Haemorrhage.

Article Citation: Kanwal S, Javed A, Saba S, Gillani AB. Comparison of efficacy of intramyometrial versus intramuscular prostaglandin F2a (PGF2a) in the management of primary postpartum hemorrhage due to uterine atony. Professional Med J 2021; 28(11):1656-1663.

https://doi.org/10.29309/TPMJ/2021.28.11.4750

\section{INTRODUCTION}

Defining postpartum hemorrhage (PPH) is a difficult task because of its complexity. However on the basis of blood loss volume the cut off amount is in excess of $500 \mathrm{ml}$ after vaginal delivery and more than $1000 \mathrm{ml}$ in case of operative abdominal delivery l.e cesarean section. ${ }^{1}$ if such amount of blood loss occur within first 24 hours of delivery of foetus is defined as primary $\mathrm{PPH}$, but loss of maternal blood that occur after first 24 hours till forty days of purperium is called secondary $\mathrm{PPH}^{2}$ National statistics of United States suggest that approximately $8 \%$ of direct maternal deaths are caused by $\mathrm{PPH}^{3}$ among the 7-10 maternal deaths per 100,000 live births. According to World Health Organization statistics among $25 \%$ of maternal deaths, the reason is $\mathrm{PPH}$, contributing almost 100,000 maternal deaths per year worldwide. $\mathrm{PPH}$ due to uterine atony increased from $1 \%$ to $3.4 \%$ in recent decade from 1999 to 2009. Morbidly adherent placenta was the major risk factor for $\mathrm{PPH}$ as a whole. ${ }^{4}$

Inability of uterine musculature to contract actively after expulsion of foeto placental unit leading to uterine relaxation is the commonest reason for primary $\mathrm{PPH}$. Other causes include placental cotyledons or membranes remain adherent badly with uterine decidua or myometrium, and traumatic laceration to vaginal epithelium or actively bleeding cervical lips injury. Ruptured uterus, clotting disorders and uterine inversion are rare, but often dramatic presentation of heavy per vaginum bleeding just after delivery. Frequency of primary $\mathrm{PPH}$ is more among primigravida ${ }^{5}$ with prolonged labour, maternal obesity ${ }^{6}$, good size baby $^{7}$, multiple gestations ${ }^{8}$, and in patients presented with antepartum haemorrhage. Grand 
multiparity itself does not seem to be a risk factor, irrespective of any social class. ${ }^{7,9}$

The incidence of complication due to primary $\mathrm{PPH}$ depends upon nutritional status of the mother, haematocriet or haemoglobin concentration at the time of delivery, access to health care facility and early intervention in addition to amount of blood loss, so the actual incidence of complication is unknown. ${ }^{10} \mathrm{PPH}$ may complicates maternal condition by developing obstetrical DIC, acute renal shut down due to hypovolemia, liver failure or ARDS, a complication of over resuscitation by crystalloid solution to treat hypovolemic shock. ${ }^{11}$

Blood loss quantification at the time of delivery depends upon the personal assessment of attending medical professional so most of the time it may be missed. One suggestion to overcome personal bias is by estimation of haemoglobin or $10 \%$ fall in haematocrit but its time consuming and at the time patient is bleeding her body compensatory mechanism is working along with active resuscitation by health care providers. ${ }^{12}$

While another group of obstetricians is in opinion of labeling PPH is, any amount of blood loss in an already compromised mother which predisposes her to haemodynamic instability ${ }^{13}$, as the patients who are already anemic or having cardio pulmonary preexisting disease, pre eclampsia or dehydration cannot cope with blood loss even less than $500 \mathrm{ml}$ and develop complications.

According to WHO recommendation every pregnancy should be grouped either low risk or high risk and high risk pregnancy should have antenatal visits or at least delivery plan in a highly equipped health care center with availability of senior obstetrician and facility of blood and blood product transfusion to reduce the maternal mortality due to $\mathrm{PPH}$. The measures taken to reduce primary $\mathrm{PPH}$ are intravenous access before second stage of labour, active management of third stage of labour and availability of blood components but despite of all these efforts sometimes primary $\mathrm{PPH}$ is unpredictable and not anticipated. So every obstetric care unit should have SOPs for the management of primary $\mathrm{PPH} .{ }^{14}$
The survival rate of actively bleeding patients depends upon the time it takes to start the treatment. Arrest of bleeding during first few golden hour of resuscitation is the main step of $\mathrm{PPH}$ management. ${ }^{15}$ Management plan for $\mathrm{PPH}$ includes examination in lithotomy position to rule out lower genital tract laceration or injuries and among most of cases the cause for primary PPH is uterine atony. Syntometrin, a first line utrotonic is in use since early 19th century. Routine use of oxytocin for active management of third stage of labour can decrease the risk of PPH in more than $40 \%{ }^{16}$ delivering mothers, but if uterus fail to contract even after use of first line utrotonic agent then uterine massage by bimanual compression should be done.

If patient donot respond to first line utrotonics and uterine compression then one should go for the 2 nd line agent. ${ }^{17}$ PGF2a is the 2 nd line agent used for management of non-responding uterine atony. Sune Bergstrom was the man who discovered prostaglandin $\mathrm{F} 2 \mathrm{a}$ series with his co-workers. ${ }^{18}$ In a case of unresponsive uterine atony to oxytocin .Use of PGF2a as a second line utrotonic agent also reduces the risk of major surgical intervention in an already compromised shock patient. ${ }^{19}$

Biochemically prostaglandin F2 alpha is a 15 -methyl analogue if used alone has $88 \%$ success rate and $95 \%$ if used with other utrotonics. ${ }^{20}$ In a study conducted by Qayum $\mathrm{M}$ et $\mathrm{al}^{21}$ study results indicate $84 \%$ success rate of prostaglandin $\mathrm{F} 2 \mathrm{a}$ when used intramyometrial route, while Oleen MA et al20 study results having success rate of 94\% with PGF2 alpha. Side effects associated with PGF2 alpha administration are increase in core body temperature, increase gut motility and vomiting with frequent rise in blood pressure which is helpful in a shock patient. ${ }^{20}$

The study determined the more effective route of prostaglandin $\mathrm{F} 2 \mathrm{a}$ administration in a nonresponding patient of primary $\mathrm{PPH}$ to first line therapy. Either intramyometrial or intramuscular route of PGF2 alpha is better to overcome uterine atony and prevent any surgical procedure in a compromised patient. 


\section{MATERIAL \& METHODS}

It was a Randomized controlled trial with nonprobability consecutive sampling, conducted at Department of Obstetrics \& Gynecology, Bahawal Victoria Hospital, Bahawalpur from February 2018 to July 2018 after approval from ethical committee (1030/DME/QAMC). Total number of patients included in the study were 266 . Patients included in study were age group of 20-39 years, with parity of 2-5,patient must have develop primary $\mathrm{PPH}$ due to uterine atony not responding to first line uterotonics I.e oxytocin either after vaginal delivery or after lower segment caesarian section. While the patients excluded from the study were those who were having primary PPH due to bleeding disorders or ruptured uterus or with retained products of conception or with genital tract injuries, patient on anticoagulant therapy, Patients with history of cardio-pulmonary disease or liver disease, renal disease or with history of hypersensitivity to Prostaglandin were also excluded from this study.

Two sixty six patients were divided into two groups. Group A included the cases who were received prostaglandin F2a injected trans abdominally into the myometrium of uterine fundus using 20 guage spinal needle and Group B included the cases who were received intramuscular prostaglandin $\mathrm{F} 2 \mathrm{a}$. Prostaglandin F2a was given at the dose of $250 \mu \mathrm{g}$ repeated at $15 \mathrm{~min}$ interval up to maximum 8 doses in both groups. All patients in both groups were evaluated for control of bleeding within 30 minutes after the initial injection. In each group, if the bleeding was arrested within $30 \mathrm{~min}$ after injecting intramuscular or intramyometrial PGF2a then the approach was labeled as successful, otherwise it was labeled as unsuccessful. Data was analyzed by using SPSS version 20.0. Age, parity and $\mathrm{Hb} \%$ were presented as mean and standard deviation. Outcome variables like efficacy of intramuscular and intramyometrial PGF2 a were presented by frequency and percentages. Comparison between the groups with respect to efficacy of both regimens was analyzed by Chi-square test. P-value $\leq 0.05$ will be considered as statistically significant. Effect modifiers were controlled by stratification of data in terms of age, parity, and $\mathrm{Hb} \%$. Post-stratification chi-square was applied to see the effect of these on outcome variables and $p$-value $\leq 0.05$ was taken as significant.

\section{RESULTS}

Age range in this study was from 20 to 39 years with mean age of $27.04 \pm 4.21$ years. The mean age of women in group $A$ was $26.94 \pm 4.43$ and in group B was $26.21 \pm 4.09$ years $(p=0.005)$. Majority of the patients $167(62.78 \%)$ were between 21 to 30 years of age as shown in Table-I.

Percentage of patients according to hemoglobin levels in both groups are shown in Table-II. Parity included in this study was from 2-5 with mean 2.92 \pm 0.91 . The mean parity in group $A$ was $2.92 \pm$ 0.87 and in group $B$ was $2.93 \pm 0.98(p=0.8579)$. Majority of the patients 125 (46.99\%) were para-2 as shown in Table-III.

There was arrest of bleeding within 30 minutes in $110(82.71 \%)$ patients in Group A while in Group $B$, it was seen in $122(91.73 \%)$ patients. So, efficacy was $82.71 \%$ in group A (Intramyometrial group) and $91.73 \%$ in group B (Intramuscular group) with $p$-value of 0.0276 as shown in TableIV \& Figure-1. Comparison of efficacy between two groups in terms of parity, age of patients and hemoglobin levels has shown in Table-V, VI and VII respectively.

\begin{tabular}{|c|c|c|c|c|c|}
\hline \multirow{2}{*}{ Age (years) } & \multirow{2}{*}{$\begin{array}{c}\text { Group A }(n=133) \\
\text { No. of Patients (\%age) }\end{array}$} & \multicolumn{2}{|c|}{ Group B $(n=133)$} & \multicolumn{2}{|c|}{ Total $(n=266)$} \\
\hline & & No. of Patients & \%age & No. of Patients & \%age \\
\hline $21-30$ & $82(61.65 \%)$ & 85 & 63.91 & 167 & 62.78 \\
\hline $31-39$ & 51 (38.35\%) & 48 & 36.09 & 99 & 37.28 \\
\hline Mean \pm SD & $26.94 \pm 4.43$ & \multicolumn{2}{|c|}{$26.21 \pm 4.09$} & \multicolumn{2}{|c|}{$27.04 \pm 4.21$} \\
\hline
\end{tabular}




\begin{tabular}{|c|c|c|c|c|c|}
\hline \multirow{2}{*}{$\mathrm{Hb} \%$ (g/dl) } & \multirow{2}{*}{$\begin{array}{c}\text { Group A }(n=133) \\
\text { No. of Patients (\%age) }\end{array}$} & \multicolumn{2}{|c|}{ Group B $(n=133)$} & \multicolumn{2}{|c|}{ Total $(n=266)$} \\
\hline & & No. of Patients & \%age & No. of Patients & \%age \\
\hline $6-8 \mathrm{~g} / \mathrm{dl}$ & $19(14.29 \%)$ & 20 & 15.04 & 39 & 14.66 \\
\hline$>10 \mathrm{~g} / \mathrm{dl}$ & 69 (51.88\%) & 66 & 49.62 & 135 & 50.75 \\
\hline Mean \pm SD & $10.78 \pm 1.11$ & \multicolumn{2}{|c|}{$10.55 \pm 1.17$} & \multicolumn{2}{|c|}{$10.71 \pm 1.07$} \\
\hline
\end{tabular}

\begin{tabular}{|l|c|c|c|c|c|}
\hline \multirow{2}{*}{ Parity } & Group A (n=133) & \multicolumn{2}{c|}{ Group B (n=133) } & \multicolumn{2}{c|}{ Total (n=266) } \\
\cline { 2 - 6 } & Frequency (\%age) & Frequency & \%age & Frequency \\
\hline 2 & $64(48.12 \%)$ & 61 & 45.86 & 125 & 20.68 \\
\hline 3 & $27(20.30 \%)$ & 28 & 21.05 & 67 & 25.19 \\
\hline 4 & $31(23.31 \%)$ & 36 & 6.02 & 19 & 7.14 \\
\hline 5 & $11(8.27 \%)$ & 08 & & $2.92 \pm 0.91$ \\
\hline
\end{tabular}

Table-III. \%age of patients according to parity in both groups.

$P$ value is 0.8579 which is not statistically significant

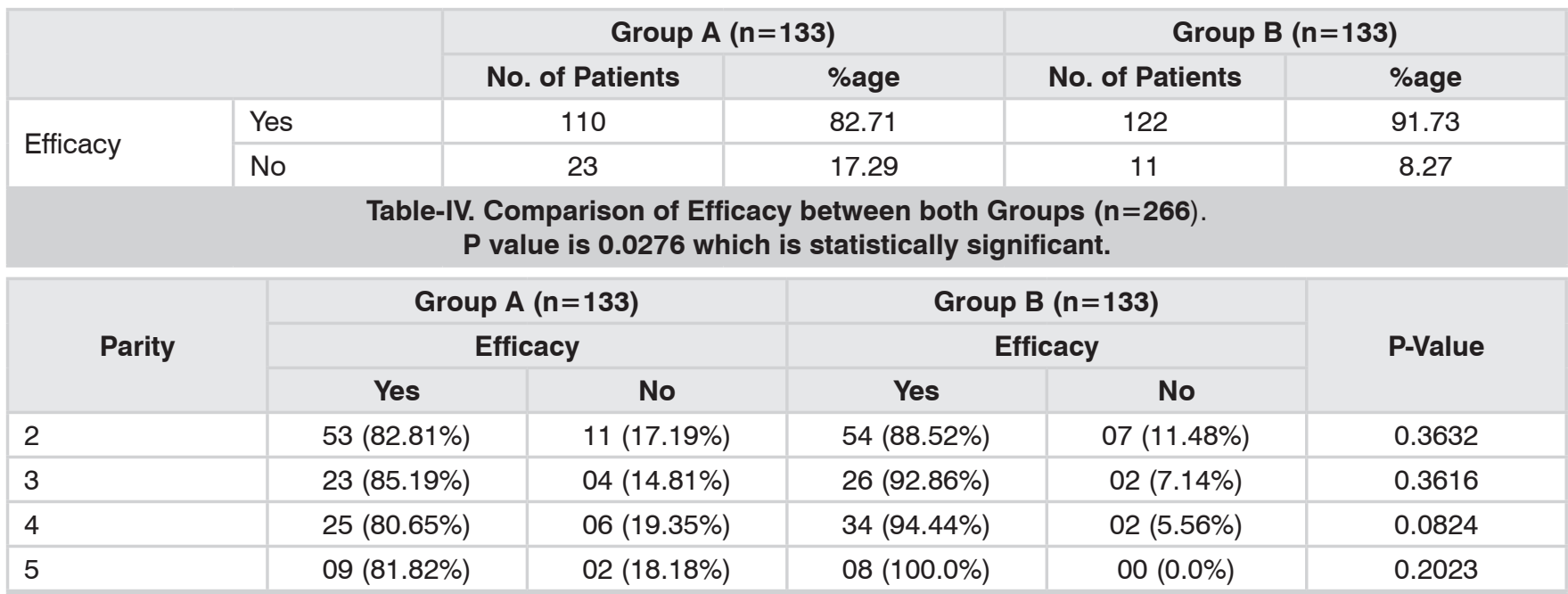

Table-V. Comparison between efficacies of both groups according to parity.

\begin{tabular}{|c|c|c|c|c|c|}
\hline \multirow{3}{*}{ Age of Patients } & \multirow{2}{*}{\multicolumn{2}{|c|}{$\begin{array}{c}\text { Group A }(n=133) \\
\text { Efficacy }\end{array}$}} & \multirow{2}{*}{\multicolumn{2}{|c|}{$\begin{array}{c}\text { Group B }(n=133) \\
\text { Efficacy }\end{array}$}} & \multirow{3}{*}{ P-Value } \\
\hline & & & & & \\
\hline & Yes & No & Yes & No & \\
\hline 20-30 years & $72(87.80 \%)$ & $10(12.20 \%)$ & $81(95.29 \%)$ & $04(4.71 \%)$ & 0.0808 \\
\hline 23-39 years & $38(74.51 \%)$ & 13 (25.49\%) & 41 (85.42\%) & 07 (14.58\%) & 0.1768 \\
\hline
\end{tabular}

Table-VI. Comparison between efficacy of both groups according to age.

\begin{tabular}{|c|c|c|c|c|c|}
\hline \multirow{3}{*}{$\mathrm{Hb} \%$ (g/dl) } & \multirow{2}{*}{\multicolumn{2}{|c|}{$\begin{array}{c}\text { Group A }(n=133) \\
\text { Efficacy }\end{array}$}} & \multirow{2}{*}{\multicolumn{2}{|c|}{$\begin{array}{c}\text { Group B }(n=133) \\
\text { Efficacy }\end{array}$}} & \multirow{3}{*}{ P-Value } \\
\hline & & & & & \\
\hline & Yes & No & Yes & No & \\
\hline $6-8 \mathrm{~g} / \mathrm{dl}$ & 16 (84.21\%) & 03 (15.79\%) & 19 (95.0\%) & 01 (5.0\%) & 0.267 \\
\hline$>8-10 \mathrm{~g} / \mathrm{dl}$ & 37 (82.22\%) & 08(17.78\%) & 43 (87.76\%) & 04 (12.24\%) & 0.1871 \\
\hline$>10 \mathrm{~g} / \mathrm{dl}$ & 57 (82.61\%) & 12 (17.39\%) & 60 (90.91\%) & 06 (9.09\%) & 0.1561 \\
\hline
\end{tabular}

Table-VII. Comparison between efficacy of both groups according to $\mathrm{Hb} \%$. 


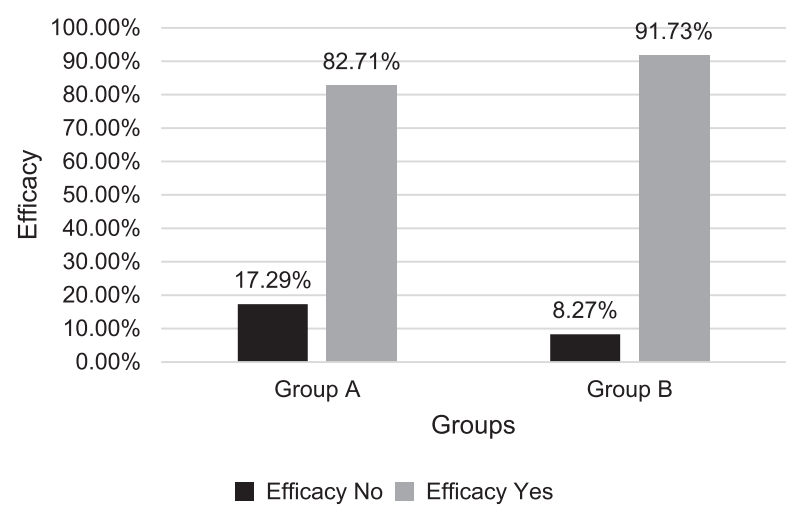

Figure-1. Efficacy of both groups $(n=266)$.

\section{DISCUSSION}

Most common cause of post-partum haemorrhage is the failure of uterine muscle to contract and retract after expulsion of fetoplacental unit and atonic uterus is the uterus which do not respond to effective uterotonic drugs. Uterine atony is the commonst reason of high maternal mortality in most of the developing countries of the world since long ago. But fortunately mothers of this century are blessed of having a group of effective utrotonics available at health care facilities to prevent and treat the uterine atony.

In early 19th century a large bull's bladder distended with water' were placed in atonic uterus to achieve temponade effect while use of vinegar or iron perchloride as douching agent in atonic uterus was also reported in review of historical management of uterine atony. ${ }^{22,23}$ The first drugs used as uterotonics were ergot alkaloids which were the product of a fungus Claviceps purpurea that grow on rye followed by oxytocin and then prostaglandins are available as a blessing for obstetrician. Ergot was referred by John Stearns in 1808 , as a labour augmenting agent. ${ }^{24}$ But till the end of the 19th century lethal side effects were reported with the use of ergot derivatives and now there use in routine practice is obsolete.

Use of ergot as labour accelerating agents led to uterine hyper stimulation causing still birth of new born and development of precipitated labour hampered its use. Later on, it was used after delivery of foetus and placenta for prevention and treatment of post-partum haemorrhage as it caused tonic contraction of parturent uterus. Focus was diverted toward its role in preventing and treating postpartum hemorrhage at the time when maternal mortality in England approached to one in 20 birth around $1870 .{ }^{25}$

In 1909 Sir Henry Dale ${ }^{26}$ discovered Oxytocin, a miracle utrotonic agent which was a hypothalmic polypeptide released by posterior pituitary, later on synthesized by du Vigneaud ${ }^{27}$ in 1954. Sir du Vigneaud was awarded by Nobel Prize for his great work.

The third group of uterotonics comprises the ever-expanding prostaglandin family. The prostaglandins were discovered in 1935 by a group led by Swedish physiologist Ulf von Euler ${ }^{28}$ discovered the ever expanding prostaglandiene family first time in the extracts of seminal vesicles of human semen. He proved that prostaglandins cause uterine contraction and decreases blood pressure. Prostaglandins, as having the ability of strong myometrial contractile activity, are increasingly used as adjunct therapy to treat postpartum hemorrhage resulting from uterine atony in addition to oxytocin and ergometrin. The route for administration for prostaglandins may be deep intramuscular injection or by direct injection in uterine myometrium. According to one study, intramyometrial injection of prostaglandin acts quickly when administered under direct vision at Cesarean section or transvaginally after vaginal delivery or transabdominally by 20 gauge spinal needle. ${ }^{29,30}$

The countra indications for the use of PGF2 alpha are cardiopulmonary disorder, history of asthma, high grade fever due to their vasoconstrictive and Broncho constrictive effects and hypersensitivity to prostalandn. Side effects of carboprost a PGF2 alpha includes nausea, vomiting, diarrhea, high grade fever and bronchospasm. Carboprost is also light- and heat-sensitive and should be kept at $4^{\circ} \mathrm{C} .{ }^{31}$

This randomized controlled study has compared the intramuscular with intramyometrial PGF2a in the management of primary postpartum hemorrhage due to uterine atony. The mean age 
of patients in this study was $27.04 \pm 4.21$ years with majority of patients i.e. $62.78 \%$ were between 21 to 30 years of age. These results were very much comparable with Qayum $\mathrm{M}$ et $\mathrm{al}^{21}$ study who had shown a mean age of 28.5 years. Akhtar $\mathrm{Z}$ et $\mathrm{al}^{32}$ in his study had shown a mean age of 29 years which is a little higher than this study.

Parity included in this study was from 2-5 with mean parity of $2.92 \pm 0.91$. Akhtar $Z$ et al32 had observed parity of $4.20+3.53$ in his study which is a much higher as compared to our study. This difference was also because range of parity included in our study was less. In a study done by Akhtar $Z$ et $\mathrm{al}^{32}$, 32\% were primiparous, $40 \%$ were multipara, and $28 \%$ were grand multipara. Similar results were also reported by Toppozada et al. $^{33}$ In our study, majority of the patients i.e. $46.99 \%$ were para-2 as we had not included the primiparous in our study. Qayum $\mathrm{M}$ et $\mathrm{al}^{21}$ has also shown majority of multiparous patients.

Prostaglandin F2 alpha can be given locally (Intramyometrially) and systemically (deep intra muscular infusion). Reported efficacy was higher with deep intramuscular route of administration of PGF2 alpha. Successful arrest of atonic hemorrhage is reported in $13 / 14$ patients by Bigrigg and colleagues. ${ }^{34}$ The largest case series to date20 involved a multicenter surveillance study of 237 cases of postpartum hemorrhage refractory to standard oxytocin and reported an efficacy of $88 \%$. There was arrest of bleeding within 30 minutes in $82.71 \%$ patients in Intramyometrial group while in Intramuscular group, it was seen in $91.73 \%$ patients in this study. So, efficacy was $82.71 \%$ in Intramyometrial group and $91.73 \%$ in Intramuscular group in our study. Oleen and Mariano ${ }^{20}$ (1989) had found $94.6 \%$ success rate by using Prostaglandin F2 alpha intramuscularly which is very much comparable to our results. This superior effect of intramuscular injection of 15-methyl Prostaglandin F2 alpha to that of Intramyometrially Prostaglandin F2 alpha in producing sustained tetanic contraction has also been reported by Zahradnik et al. ${ }^{32}$

In a study conducted by Corson SL et al ${ }^{34}$ Akhtar $\mathrm{Z}$ et $\mathrm{al}^{32}$ has demonstrated that intramuscular and intramyometrial administration of prostaglandin F2 alpha giving success rate of $88 \%$. Similar success rates were also published by Toppozada $\mathrm{M}$ et $\mathrm{al}^{33}(83 \%)$, Hayashi $\mathrm{RH}$ et $\mathrm{al}^{35}$ (8 6\%) and Oleen et $\mathrm{al}^{20}(94.9 \%)$.

\section{CONCLUSION}

So intramuscularprostaglandinF2aadministration is is associated with better efficacy for the treatment of primary PPH due to uterine atony as compared to intramyometrial route. On the basis of our study results and review of previous studies intramuscular route is preferred over intra myometrial route for injecting prostaglandin $\mathrm{F} 2 \mathrm{a}$ in management of primary postpartum hemorrhage to avoid the surgical intervention which may result in serious anesthesia or surgery related complications in an already compromised patient. Moreover intra muscular route do not require experties for administration which are essential with intramyometrial route.

\section{Copyright @ 30 Mar, 2021.}

\section{REFERENCES}

1. Baskett TF. Complications of the third stage of labour. In: Essential Management of Obstetrical Emergencies. 3rd ed. Bristol, England: Clinical Press; 1999:196-201.

2. Rogars MS, Chang AMZ. Postpartam hemorrhage and other problems of the third stage In: James DK, Steer PJ, Weiner CP, Gonik B, editors High Risk Pregnancy management options. Philadelphia: Saunders; 2006. p1559-78.

3. Berg CJ, Atrash HK, Koonin LM, Tucker M. Pregnancyrelated mortality in the United States, 1987-1990. Obstet Gynecol. 1996; 88(2):161-7.

4. Lutomski J, Byrne B, Devane D, Greene R. Increasing trends in atonic postpartum haemorrhage in Ireland: An 11-year population-based cohort study. $\mathrm{Br} J$ Obstet Gynecol. 2012; 119(3):306-14.

5. Gilbert L, Porter W, Brown VA. Postpartum haemorrhage: A continuing problem. $\mathrm{Br} \mathrm{J}$ Obstet Gynaecol. 1987; 94:67-71.

6. Aisaka K, Ando S, Kokuho K, Tawada T, Kaneda S, Yoshimatsu J, et al. Effects of obesity and weight gain during pregnancy on obstetrical factors. Acta Obstet Gynaecol Jap. 1988; 63:1851-8. 
7. Stones RW, Paterson CM, Saunders NSTG. Risk factors for major obstetric haemorrhage. Europ $\mathrm{J}$ Obstet Gynecol Reprod Biol. 1993; 48:15-8.

8. Combs CA, Murphy EL, Laros RK. Factors associated with postpartum haemorrhage with vaginal birth. Obstet Gynecol. 1991; 77:69-76.

9. Drife J. Management of primary postpartum haemorrhage. Br J Obstet Gynaecol. 1997; 104:275-7.

10. Gilstrap LC, Ramin SM. Postpartum hemorrhage. Clinic Obstet Gynecol. 1994; 37:824-30.

11. Bonnar J. Massive obstetric haemorrhage. Baillieres Best Prac Res Clinical Obstet Gynaecol. 2000; 14(1):118.

12. Cunningham FG, Gant NF, Leveno KJ, et al, eds. Conduct of normal labor and delivery. In: Williams Obstetrics. ed. New York, NY: McGraw-Hill; 2001:320-5.

13. Anderson JM, Etches D. Prevention and management of postpartum hemorrhage. Am Fam Physic. 2007; 75(6):875-82.

14. Barbieri RL. Planning reduces the risk of maternal death. This tool helps. Obstet Gynecol Manag. 2009; $21(8): 8-10$.

15. Chandraharan E, Arulkumaran S. Surgical aspects of postpartum haemorrhage. Best Pract Res Clin Obstet Gynaecol. 2008; 22:1089-10.

16. Prendiville W, Elbourne D, Chalmers I. The effects of routine oxytocic administration in the management of the third stage of labour: An overview of the evidence from controlled trials. $\mathrm{Br} \mathrm{J}$ Obstet Gynaecol. 1988; 95:3-16.

17. Ramanathan G, Arulkumaran S. Postpartum hemorrhage. J Obstet Gynaecol. 2006; 28:967-73.

18. Bergstrom S, Ryhag ER, Samuelson B, Sjovall J. The structure of prostaglandin E, F1, F2. Acta Chemica Scandinavica 1962; 16:501-2.

19. Jamila $M$, Jahangir $S$, saddique $I$. The role of prostaglandin in the management of primary postpartum hemorrhage due to uterine atony and the impact of its use on the need for obtetrics hysterectomy. J'Postgrad Med Inst. 2011; 18:293-99.

20. Oleen MA, Mariano JP. Controlling refractory atonic postpartum hemorrhage with hemabate sterile solution. Am J Obstet Gynecol. 1990; 162(1):205-8.
21. Qayum M, Nasreen K. Efficacy of intramyometrial prostaglandin in the management of primary postpartum hemorrhage due to uterine atony in the multipara after failure on conventional therapy. Pak Armed Forces Med J. 2010;60:12-

22. Davis DD. The principles and practice of obstetric medicine. London: Rebman, 1896:602.

23. De Costa C. St Anthony's fire and living ligatures: A short history of ergometrine. Lancet. 2002; 359:176870 .

24. Thoms $\mathrm{H}$. John Stearns and pulvis parturiens. Am J Obstet Gynecol. 1931; 22:418-23.

25. Edgar JC. The Practice of Obstetrics. Philadelphia: Blakiston, 1913:475-7.

26. Dale $\mathrm{HH}$. The action of extracts of the pituitary body. Biochem J. 1909; 4:427-47.

27. Du Vigneaud V, Ressler C, Swan JM. The synthesis of an octapeptide amide with the hormonal activity of oxytocin. J Am Chem Soc. 1954; 75:4879-80.

28. von Euler $H$, Adler E, Hellstrom H. On the specific vasodilating and plain muscle stimulating substance from accessory genital glands in man and certain animals (prostaglandin and vesiglandin). J Physiol. (London) 1937; 88:213-34.

29. Jacobs M, Arias F. Intramyometrial PGF2a in treatment of severe postpartum hemorrhage. Obstet Gynecol. 1980; 55:665-6.

30. Oleen MA, Mariano JP. Controlling refractory postpartum hemorrhage with hemabate sterile solution. Am J Obstet Gynecol. 1990; 162:205-8.

31. Hankins GD, Berryman GK, Scott RT, Hood D. Maternal arterial desaturation with 15-methyl prostaglandin F2 alpha for uterine atony. Obstet Gynecol 1988; 72:367-70.

32. Akhtar Z, Qazi Q, Khan I. Prostaglandin f2 alpha: an effective alternate to surgical control of postpartum hemorrhage in uterine atony. J Postgraduate Med Inst. 2010; 24(1):27-30.

33. Topozada M, El-Bossaty M, El-Rehman HA, El-Din $\mathrm{AH}$. Control of intractable atonic post-partum hemorrhage by 15-methyl prostaglandin F2 alpha. Obstet Gynecol. 1981; 58:327-30.

34. Bigrigg A, Chui D, Chissell S. Use of intramyometrial 15-methyl prostaglandin $\mathrm{F} 2 \mathrm{a}$ to control atonic postpartum haemorrhage following vaginal delivery and failure of conventional therapy. $\mathrm{Br} \mathrm{J}$ Obstet Gynaecol. 1991; 98:734-6. 
35. Hayashi RH, Castillo MS, Noah ML. Report of confidential Enquiries into maternal Management of severe postpartum hemorrhage deaths in the United Kingdom, 1985-1987. With a prostaglandin F2 alpha analogue. Obstet London: HMSO, 1991. Gynecol. $1984 ; 63: 806-8$.

\begin{tabular}{|c|c|c|c|}
\hline \multicolumn{4}{|c|}{ AUTHORSHIP AND CONTRIBUTION DECLARATION } \\
\hline No. & Author(s) Full Name & Contribution to the paper & Author(s) Signature \\
\hline 1 & Saira Kanwal & Manuscript writing. & \\
\hline 2 & Aisha Javed & Data analysis. & $\begin{array}{l}\text { Ancer I aved } \\
\text { Siche. }\end{array}$ \\
\hline 3 & Sidra Saba & Data collection. & \\
\hline 4 & Afifa Batool Gillani & Editing \& References. & 100 \\
\hline
\end{tabular}

